past few years. There was no radiological evidence of malformation and all but one were boys. Relapse occurred after one month (two cases), three months, and 11 months. The last of these had unilateral ureteric reflux up to the kidney. This was absent when the cystogram was repeated two years later.

These findings may reflect the stringency of our follow-up arrangements. We plan to see children with neonatal urinary tract infection every month until such time as the urines have been free of leucocytes for a period of 12 months. Our screening test is microscopy for leucocytes, done by the clinician; if there is leucocyturia diagnostic urine is obtained by bladder puncture. A considerable proportion of these children have been followed for longer periods, but we have not seen any instances of recurrent leucocyturia after the children have been cleared according to the above criteria.-I am, etc.,

West Middlesex Hospital

N. J. O'DOHERTY Isleworth, Midd

\section{Hepatitis Contracted in the Course of Employment}

SIR,-The article by your Legal Correspondent (4 December, p. 632) is to be welcomed for underlining the far from generous compensation offered to the widows of doctors who die from disease contracted in the course of their duties.

We would point out that the impression is given in the article that a discretionary injury award up to two-thirds of the officer's average remuneration can be made. While this is true if he does not die but is totally disabled (an unlikely event with serum hepatitis), in the event of his death his wife can only receive one-third of this-that is, two-ninths of his average remuneration.

These facts again underline the very poor cover offered to N.H.S. employees by the superannuation scheme. We believe that many doctors, especially the more junior ones, are quite unaware of how little their widows will receive if they die, and these facts should be more widely known by all N.H.S. medical staff.

We agree that there is a strong case for the acceptance of serum hepatitis as a prescribed disease under the Industrial Injuries Acts and for an immediate increase in the injury allowance paid to widows and dependants.-We are, etc.,

\section{Phillip HaRris}

Chairman, Medical and Dental Staff Committee Royal Infirmary Edinburgh

\section{Consultant Grades and Continuity of Care}

SIR,-Once more I read (Supplement, 11 December, p. 73) of a conference which overwhelmingly threw out a proposal for a subconsultant grade.

I wonder how many psychiatrists attended the meeting. Whatever may be true of patients in other specialties, psychiatric patients need continuity of care and do better with therapists who are available in terms of time and place rather than in terms of status. Rotating registrars cannot satisfy this need. Maybe this is why psychiatric nurses, who get to know their patients well, are so important. It is not brilliant diagnostic skill most of our clients require; it is an informed, concerned relationship that continues long enough to produce change.

Moreover, the medical assistant grade (foolishly named as it is) provides the relative permanency and level of salary which a number of doctors are happy to accept. Married women who have acquired skill and experience, but do not seek the responsibilities and burdens of consultantship, are an important case in point.

Can I make a plea for rational reappraisal of these needs and suggest that we retrieve the baby from the bath water?-I am, etc., Ross Clinic,
Aberdeen

J. K. W. MORRICE

\section{Humidifiers in Anaesthesia}

SIR,-Dr. J. N. Lunn and his colleagues (11 December, p. 653) describe as "inherently safe" a gas humidification procedure during anaesthesia in which the water reservoir is maintained at $40^{\circ} \mathrm{C}$. Though the apparatus they describe may indeed prove satisfactory in preventing heat loss, it will create ideal conditions for the proliferation of Pseudomonas and other opportunistic pathogens.

The importance of anaesthetic apparatus as a reservoir of infection, especially with Gram-negative bacilli, has now been fully established, 2 yet Dr. Lunn and his colleagues do not even mention the problem. As an interim measure, all humidifiers should be equipped with small immersion heaters, so that the water can at least reach boiling point at frequent intervals. Medical microbiologists who have to cope with the consequences of infection from ventilators and other anaesthetic equipment however look forward to the millenium when all such equipment will at last be built completely out of heat-sterilizable materials, and when no patient has to breathe through apparatus which has been used and contaminated by others.-I am, etc.,

Department of Bacter:ology,

ter Medical School,

London S.W.1

1 Phillips, I., and Spencer, G., Lancet, 1965, 2, 1325 .

Bassett, D. J. C., Proceedings of the Royal Society
of Medicine, 1971, 64, 980.

\section{Obesity and Smoking Habits}

SIR,-I read with interest Dr. T. Khosla and Professor C. R. Lowe's communication on "Obesity and Smoking Habits" (2 October, p. 10) and the ensuing correspondence (30 October, p. 298; 4 December, p. 625).

In a recent M.R.C. project (undertaken jointly with the Hebrew University, Jerusalem, under the auspices of the International Biological Programme) anthropometric and physiological studies were carried out in Israel on immigrants from the Yemen and from Kurdistan. The subjects were aged 20-30, and the proportion of cigarette smokers was similar to that in the U.K. or America. Among both Yemenite and Kudish men smokers (all levels of consumption) were taller than non-smokers, but there was little difference in weight. The non-smokers did, however, have a higher value for upper arm skinfold thickness (mean of readings over biceps and triceps). The numbers here were small, and it would be interesting to know if any quantitative assessment of leanness-fatness has been made in a larger series of smokers and nonsmokers compared for "obesity." Such measurements might be of greater relevance than "overweight" based on standard tables or a weight-height ratio in assessing the risk of "obesity" associated with smoking status.

Incidentally, might I be permitted gently to challenge Dr. G. Pincherle's description (30 October, p. 298) of smokers of 1-19 cigarettes per day as "those who exhibit moderation in non-smoking." Surely no-one in that category is a non-smoker, and 19 a day is hardly moderation.-I am, etc.,

JOHN A. LOURIE

University College Hospital Medical School, University Coll

\section{Respiratory Syncytial Virus in Hospital Cross-infection}

SIR,-Dr. R. K. Ditchburn and others (18 September, p. 671) writing about the spread of respiratory syncytial (R.S.) virus in a hospital for children open a debate on a very serious problem-namely, how to reduce the risk of cross-infection of children hospitalized because of any infectious disease, and especially one caused by viruses.

We have reported an outbreak of acute respiratory illnesses caused by R.S. virus in a home for infants consisting of three ward rooms. ${ }^{1}$ All the infants (15 aged 1-13 months) as well as the 12 staff members were healthy during the week before the outbreak.

The first infant who became ill (4 April, 1964) was a 13-month-old boy from a room where there were six other infants between 5 and 8 months old. He had been away from the home for five weeks, and the day after his return he fell ill with fever, nasal discharge, and a cough. Chest $x$-ray showed bronchopneumonia. Paired sera from this child showed a significant rise in complement fixing (C.F.) antibody titre against R.S. virus.

From 6 to 10 April all the infants in this ward developed acute respiratory illnesses. Between 11 and 16 April a further three infants (aged 1-1 $\frac{1}{2}$ months) in one room on the second floor showed clinical signs of acute respiratory illness, and between 18 and 30 April all the five infants (aged $1 \frac{1}{2}-5$ months) in the other room on the second floor also became ill in succession. When this outbreak of acute respiratory illness had passed, all of the 15 children had been ill with fever, nasal discharge, and coughs. One-third had had signs of lower respiratory tract disease, such as bronchitis, bronchiolitis, and bronchopneumonia. These last mentioned infants were all seriously ill but survived. The incubation period for R.S. virus infection was estimated at 3-5 days. R.S. virus was recovered from nasopharyngeal and/or throat swabs from 13 out of 15 infants. Complement fixation tests against R.S. antigen showed at least four-fold rises of antibody in seven out of 15 paired sera, including sera from two children from whom virus was not isolated. R.S. virus was recovered two days before the onset of illness as well as nine days after onset. There was no rise 
in C.F. antibody titre against adenovirus, influenza $A$ and $B$, parainfluenza 1, 2, and 3 , mumps, or herpes simplex virus.

The slow transmission of infection from case to case in this home for infants suggests that R.S. virus infection may be considerably less contagious than measles or chickenpox. The transmission between the rooms may have been caused by some member of the staff. Two of them had a slight coryza and one had coryza and fever during the investigation. However, in none of our staff members studied, including the three mentioned above, could R.S. virus infection be established. According tc Johnson et al. ${ }^{2}$ reinfection with R.S. virus 1 lay occur and is perhaps quite common.

Dr. Ditchburn and colleagues stated that even when special precautions are taken to exclude infection, such as treatment in cubicles, the cross-infection with R.S. virus is not effectively prevented. One reason is that adults with mild respiratory symptoms may be the vehicle by which R.S. virus is transmitted. I agree fully with this statement, but in my opinion children with acute respiratory illnesses and other infections should be treated in wards especially built for the care of patients with such diseases and with a staff well trained in taking care of children with infections. In Sweden every county has a clinic for infectious diseases in connection with a big general hospital. Most of these Swedish departments for infectious diseases are very modern, with several wards with only single-bed rooms. All these rooms are separately ventilated and each has one sluice (air lock) to the corridor and another one to the outside of the building. The patients are taken into the ward room from the outside only. $X$-rays are taken at the bedside and only exceptionally are patients transported through the corridors. This avoids airborne transmission of infectious agents between patients, but does not avoid transmission of infectious agents from the staff to the patients. as seems to have been the case during the outbreak reported by Dr. Ditchburn and others. If, however, the staff members are well trained in prophylactic measures, and if they are not allowed to work when they are infected, the risk for cross-infection is reduced to a minimum. In this connexion it can be mentioned that we have treated several children with proved R.S. virus infection in our paediatric wards for infectious diseases without any spread to other hospitalized children.-I am, etc.,

GÖRAN STERNER

University Clinic for Infectious Diseases, Danderyd Hospital,

1 Sterner, G., Wolontis, S., Bloth, B., and de Hevesv, G., Acta Paediatrica Scandinavica, 1966, 55,273 .

2 Johnson. K. M., Bloom, H. H. Mufson, M. A., Medicine, 1962, 267, 68.

\section{Stroke Units}

SIR,-I was interested in your leading article (6 November, p. 313) suggesting the creation of "regional stroke units." I was interested too in the comments of Dr. Bernard Isaacs (20 November, p. 492). Geriatricians such as Professor George Adams of Belfast and Dr. Bernard Isaacs himself have undertaken pioneer work during the past few years in the field of stroke rehabilitation.
For too long stroke rehabilitation has been one of the Cinderellas of medicine in general and of neurology in particular. Stroke is the commonest cause of severe chronic disability in the community. ${ }^{1}$ A considerable amount of research has been done into problems of pathology, hypertension, changes in cerebral blood flow, and the place of anticoagulants in the prevention of strokes. Despite all the experimental work that has been done a large number of previously active independent people are rendered useless and frequently completely dependent upon others as a result of a stroke. Research into the problem of recovery after stroke has lagged very seriously behind research into other fields. This is perhaps surprising when it is recalled that strokes present a very common problem having enormous financial and personal implications.

There are probably between 100,000 and 120,000 new strokes each year in England and Wales. ${ }^{2}$ Approximately half the people who have a stroke will survive the first month. This means that in England and Wales approximately 60,000 people per year will survive the acute episode. We estimate that between 30,000 and 35,000 of these will have a hemiplegia. It appears that about $25 \%$ of non-fatal strokes are admitted to hospital each year-approximately 15,000 . If these patients are kept in hospital for an average of 6-8 weeks at a weekly cost of $£ 70$ the cost to the nation of this problem alone will be over $£ 6,000,000$. In addition, there is the enormous cost of patients admitted to hospital who are never discharged. In making these calculations it must be said that there is very little published information about the epidemiology and natural history of cerebrovascular disease in the general population of England and Wales, though there are several excellent hospital studies.

A recent personal study in a general hospital in the South West showed that the average acute stroke inpatient received approximately half an hour's physiotherapy a day. The average amount of physiotherapy given to acute stroke patients who attended on an outpatient basis was one hour per week. A similar situation existed with speech therapy. An investigation undertaken in the same general hospital showed that the average acute dysphasic patient received ten minutes speech therapy a day. In another hospital in the same area no speech therapy was available at all. We have thus reached the situation in which patients are admitted ostensibly for rehabilitation and yet are given very little. All too frequently the patient spends his time sitting by his bed staring into space. I suspect that a similar situation exists in many acute district general hospitals throughout the country.

It seems likely that if we are to achieve reasonable results, it will be necessary to provide better and more intensive rehabilitation facilities than at present exist. $\mathrm{My}$ personal experience is that the rehabilitation programmes offered by district general hospitals are unsatisfactory. Most physiotherapy departments have neither the facilities nor the staff with which to provide the necessary treatment programme. Furthermore, some physicians doubt the value of physiotherapy and other rehabilitation procedures, as it must be conceded that very little objective work has been done on the question of the influence of therapy on recovery in the damaged central nervous system.
I submit that there is a strong case for the setting up of one or more experimental stroke units which would attempt to delineate the size of the problem, to ascertain the effect of rehabilitation techniques upon recovery, and to develop new rehabilitation methods.-I am, etc.,

Bristol

R. LANGTON HewER

1 Harris, A. I., Cox, E., and Smith, C.H.W., Handicapped and Impaired in Great Britain, Office of Population Censuses and Surveys, 2 Modern Geriatrics, 1971, 1, 368.

\section{Tetracycline and Renal Function}

SIR,-May I add to Dr. C. B. Brown's timely warning about the use of tetracycline in the presence of renal failure (13 November, p. 428). In addition to the antianabolic effect of this drug there are other considerations.

The biological half-life of tetracycline is approximately 8.5 hours in patients with normal renal function. This is prolonged to between 57 and 108 hours in patients with severe renal failure. ${ }^{1}$ The administration of tetracycline in doses of $1000 \mathrm{mg}$ a day to patients with renal failure will lead not only to a rise in blood urea due to the antianabolic effect but also to accumulation of the drug. This is often associated with an increased incidence of gastrointestinal side effects including vomiting and/or diarrhoea. The resulting sodium and water depletion may then precipitate a patient with stable chronic renal failure into severe uraemia.

The antianabolic effect of tetracycline seems to be shared by oxytetracycline, lymecycline, and demethylchlortetracycline. ${ }^{2}$ Little and Bailey have shown, however, that the administration of doxycycline to patients with varying degrees of renal failure does not lead to a rise in the blood urea level. ${ }^{2}$

The mean biological half-life of doxycycline in patients with normal renal function has been reported as 18 hours $^{3}$ and 22 hours. ${ }^{4}$ Satisfactory serum levels can be achieved in patients with normal renal function by a loading dose of $200 \mathrm{mg}$ followed by $100 \mathrm{mg}$ once daily thereafter. Mahon, Wittenberg, and Tuffnel $^{3}$ have shown that no accumulation of doxycycline occurs in patients with severe renal failure given the same dosage schedule for up to 15 days. My own unpublished observations confirm the results of Little and Bailey that the administration of doxycycline to patients with renal failure does not lead to a rise in the blood urea level. In addition, the biological half-life of doxycycline in one anephric patient and three patients with endogenous creatinine clearances of $<5 \mathrm{ml} /$ min was found to be similar to the reported estimates for patients with normal renal function (13-19 hours)

Further investigation of the effects of doxycycline administration on renal function, nitrogen balance, and sodium balance in patients with renal failure are clearly indicated, but the evidence already available suggests that doxycycline may prove to be of particular value when a broad spectrum antibiotic is required in patients with renal failure.-I am, etc.

Department of Medicine,

J. R. CURTIS

Fulham Hospital,

1 Kunin, C. M., Proceedings of the International Congress on Nephrology, Washington, 1966. 